\title{
The moderating role of socioeconomic status on level of responsibility, executive functioning, and cortical thinning during adolescence
}

\author{
Giorgia Picci ${ }^{1,2}$ (D) | Emma J. Rose ${ }^{1}$ (D) | John W. VanMeter ${ }^{3}$ (D) | Diana H. Fishbein ${ }^{1,2,4}$ (ID
}

\author{
${ }^{1}$ Program for Translational Research on \\ Adversity and Neurodevelopment (P-TRAN), \\ The Edna Bennett Pierce Prevention \\ Research Center, The Pennsylvania State \\ University, University Park, PA, USA \\ ${ }^{2}$ Department of Human Development \\ and Family Studies, Pennsylvania State \\ University, University Park, PA, USA \\ ${ }^{3}$ Center for Functional and Molecular \\ Imaging, Georgetown University Medical \\ Center, Washington, DC, USA \\ ${ }^{4}$ Frank Porter Graham Child Development \\ Institute, University of North Carolina at \\ Chapel Hill, Chapel Hill, NC, USA
}

\section{Correspondence}

Diana H. Fishbein, Department of Human Development and Family Studies, Program for Translational Research on Adversity \& Neurodevelopment (P-TRAN), Edna Bennett Pierce Prevention Research Center, Penn State University, 218 Health and Human Development Building, University Park, PA 16802, USA.

Email: dvf5211@psu.edu

\section{Funding information}

National Institute on Alcohol Abuse and Alcoholism, Grant/Award Number: 1R01AA019983-01 and 3R01AA01998302S1; Eunice Kennedy Shriver National Institute of Child Health and Human Development, Grant/Award Number: P5OHD089922

\begin{abstract}
Brain development is exquisitely sensitive to psychosocial experiences, with implications for neurodevelopmental trajectories, for better or worse. The premise of this investigation was that the level of responsibility in adolescence may relate to brain structure and higher-order cognitive functions. In a sample of 108 adolescents, we focused on cortical thickness (using FreeSurfer) as an indicator of neurodevelopment in regions previously implicated in executive functioning (EF) and examined performance on an EF task outside of the scanner, in the context of level of responsibility. We further investigated whether socioeconomic status (SES) and family stress moderated the relationship between responsibility and brain structure or EF. Findings revealed that greater responsibility was related to thinner left precuneus and right middle frontal cortex. In lower SES adolescents, greater responsibility predicted thinner left precuneus and right middle frontal cortex, which have been consistently implicated in EF. Higher SES adolescents did not show structural differences related to responsibility, however, they did exhibit better EF performance. It may be that circumstances surrounding the need for greater responsibility in lower SES households are detrimental to neurodevelopment compared to higher SES households. Alternatively, responsibility may act as a protective factor that bolsters cortical thinning in regions related to EF.
\end{abstract}

\section{KEYWORDS}

adolescence, brain development, cortical thickness, executive functioning, responsibility, socioeconomic status

\section{1 | INTRODUCTION}

Adolescence represents a developmental period typified by strength and vulnerability; a dichotomy that neuroscientists have been attempting to understand from a neurodevelopmental perspective for decades. During this time, the brain is undergoing major topological remodeling and, as such, is exquisitely sensitive to a wide range of environmental inputs, for better or for worse. On the negative end of this spectrum, adverse experiences (e.g., child maltreatment, poverty, witnessing violence) are known to contribute to poor outcomes from adolescence into adulthood, including poor self-regulation, substance abuse and other types of psychopathology (e.g., Evans \& Kim, 2013; Jaffee, 2017; Lovallo, 2013; Rossow, Felix, Keating, \& McCambridge, 2016; Wright, Fagan, \& Pinchevsky, 2013). In contrast, more positive experiences such as supportive parenting/mentoring, safe neighborhoods, well-equipped schools, and positive peer influences are predictive of healthy self-regulation and the absence of psychopathology throughout adolescence and 
into adulthood (e.g., Farley \& Kim-Spoon, 2014; Hurd, Stoddard, \& Zimmerman, 2013; Niehaus, Rudasill, \& Rakes, 2012; van der Voort et al., 2014). A significant body of research has suggested that neurodevelopmental trajectories may be altered toward or away from positive outcomes via these contextual factors.

One psychosocial influence that may mediate or moderate the effects of adversity during adolescent development but has received little attention is the level of responsibility that is expected of, or actuated by, adolescents. Adolescent responsibility is conceptually defined herein as developmentally appropriate tasks or activities that are expected or required of adolescents by caregivers in the household. Given the brain's experience dependence, a healthy degree of responsibility expected by caregivers may exert subtle, positive effects on brain development in regions associated with self-regulation and dimensions of executive functioning (EF) that are still under construction (e.g. Casey, Getz, \& Galvan, 2008). Alternatively, permissive parenting - with caregivers not having many expectations for their teen to contribute to household chores and other family needs - may place insufficient demands on neural systems to advance a healthy rate of neurodevelopment. In other words, the brain's experience dependence may translate to the ability of level of responsibility to exact subtle influences on the brain's rate of development and subsequent functioning.

There has been little research that explicitly focuses on the relationship between neurocognitive development and level of responsibility, either expected or actuated, within the household among adolescents. Studies that have focused on other outcomes report both positive and negative effects of level of household responsibility on adolescent well-being. For example, some studies have found that greater expectations for performing housework are associated with happiness. In contrast, other studies report that a higher level of responsibility is related to feelings of burden and poorer grades (Telzer \& Fuligni, 2009). Although not measured, other features of the household (e.g., parent-child relationship, emotional support, financial security) may play a crucial role. A few researchers have theorized that responsibility is largely a positive, autonomy-building experience for adolescents that may support development of self-regulation abilities and goal-directed behaviors (Raffaelli, Simpkins, Tran, \& Larson, 2018; Riggio, Valenzuela, \& Weiser, 2010; Wray-Lake \& Syvertsen, 2011). Given that maturation of EF supports the development of self-regulation, goal-direction, and other abilities, it may be the case that level of responsibility helps to shape integrity of these functions throughout adolescence (Boelema et al., 2014).

A related body of work has examined "family obligation values" in Mexican adolescents, finding that they play a beneficial role in their well-being, autonomy building, and serve to mitigate risk for psychopathology, including internalizing symptoms and substance abuse (Telzer, Fuligni, Lieberman, \& Galván, 2013; Telzer, Tsai, Gonzales, \& Fuligni, 2015). However, these findings may be dependent upon the family context in that increased family conflict and decreased resources may moderate the extent to which increased responsibility is beneficial (Telzer et al., 2013). Indeed, the parent-adolescent relationship is likely a major determinant of how adolescents respond to demands that are placed upon them in the home; for example, greater parent-adolescent conflict has been found to moderate the relationship between housework and depressive symptoms (Lam, Green, \& McHale, 2016).

Family economic strain also plays an important role in adolescents' levels of responsibility. Compared to adolescents from higher SES families, those from lower SES families tend to be tasked with higher levels of responsibility due to greater need (Tsai, Telzer, \& Fuligni, 2013). Moreover, adolescents from lower SES backgrounds with higher levels of household responsibility are more likely to use drugs (Telzer, Gonzales, \& Fuligni, 2014). Indeed, in the context of family need (e.g., decline in parental physical health), adolescents with greater household responsibility exhibit more internalizing symptoms (Telzer et al., 2015). Thus, although responsibility may generally be a positive and formative experience for adolescents, it is largely dependent upon the home context in which adolescents reside. To date, no study has examined how home context and household responsibility interface to impact adolescent neurodevelopment. Time spent engaging in household chores increases significantly from childhood to mid-adolescence, making adolescence an ideal time to study this relationship (Lam et al., 2016).

In addition to the association between economic strain and the potential burden of adolescent responsibility, economic disadvantages have consistently been linked to perturbations in neural development (for review, Johnson, Riis, \& Noble, 2016). Specifically, an array of SES indicators, such as neighborhood, family income, parental education, and the income-to-needs ratio have been reliably associated with aberrant structural brain development in economically disadvantaged compared to advantaged youths (Lawson, Duda, Avants, Wu, \& Farah, 2013; Luby et al., 2013; Nobel, Houston, Kan, \& Sowell, 2012; Noble et al., 2015; Ursache \& Noble, 2016). Notably, in youths from low SES families, relatively small differences in income can confer considerable differences in brain structure development, particularly in areas supporting EF and learning (Hair, Hanson, Wolfe, \& Pollak, 2015; Noble et al., 2015). Income differences within high SES youths do not confer the same level of neurodevelopmental deficits, suggesting that incremental income disparities in higher SES youths do not present the same risk for neurodevelopment as in lower SES youths. By and large, children from lower SES families tend to have smaller regional volumes and thinner cortical regions throughout the brain compared to those from higher SES families, suggesting a potential neurodevelopmental lag (Jednoróg et al., 2012). Regions impacted in lower SES children, including those that subserve development of EF skills, show less cortical surface area, including the inferior frontal gyrus, orbitofrontal gyrus, medial frontal gyrus, and precuneus (Noble et al., 2015). Other studies have found that SES may moderate patterns of cortical thinning such that in lower SES, age-related cortical thinning is initiated earlier and follows a curvilinear pattern, whereas in higher SES youth, cortical thinning is initiated later and follows a more linear pattern (Piccolo, Merz, He, Sowell, \& Noble, 2016). Altogether, these findings suggest that examining SES as a moderator in the relationship between 
responsibility and cortical thinning may be critical to discerning the complex relationships among contextual factors in contributing to neurodevelopment.

The present investigation was designed to explore relationships between adolescent responsibility and the confluence of responsibility and contextual factors (i.e., SES and family stress) on adolescent neurodevelopment (Zhou, Lebel, Treit, Evans, \& Beaulieu, 2015). There are no previous studies to guide a priori expectations for which brain regions are likely to be recruited during responsible activities. In fact, responsibility is not just a task-oriented action; it is more of a parental technique and overall expectation for child behavior with potential to dynamically influence development. Thus, hypotheses were derived from conceptualizations of responsibility and the neural regions most likely to be affected by such ongoing expectations and experiences. We focused on cortical thickness as an indicator of maturation in neural regions that subserve EF and behavioral self-regulation. By and large, previous research indicates that many cortical regions reach peak thickness at approximately 10-12 years old, followed by a steady decline in cortical thickness due to pruning that stabilizes in the mid-to-late twenties (Fjell et al., 2015; Giedd et al., 1999; Tamnes et al., 2017; Vidal-Pineiro et al., 2019). Brain regions examined here have generally been found to follow a similar trajectory; for example, longitudinal work has shown that the frontal and parietal cortices begin to undergo significant dendritic pruning and myelination around ages 11-12 (Giedd et al., 1999; Giedd, 2004). Therefore, in our slightly older sample (11-13 years old), evidence of decreased cortical thickness with greater levels of responsibility may indicate more normative brain development. It was hypothesized that a higher level of responsibility would be associated with decreased cortical thickness in brain regions subserving EF and self-regulatory behaviors (e.g., superior, orbital and middle frontal cortices, precuneus, and anterior cingulate). In addition, we considered performance on a problem-solving task outside the scanner in the context of adolescents' level of responsibility, with the expectation that levels of performance and responsibility would be positively correlated.

Second, we considered the influence of contextual factors that may mitigate positive effects of responsibility on neurodevelopment. SES and family stress were included as proxies for the degree to which adolescents have a higher level of responsibility as a function of adversity, as opposed to a teaching or skill-building tool applied by parents in higher-income households. It was hypothesized that lower SES adolescents and those with greater family stress would have thicker regions in conjunction with greater responsibility, while adolescents from higher-income households and who have less family stress would demonstrate a more normative pattern of thinning cortical regions in the context of greater responsibility. Furthermore, it was predicted that SES and family stress would moderate the relationship between responsibility and performance on a problem-solving task (i.e., Stockings of Cambridge). Based on prior evidence (e.g., Johnson et al., 2016), economic and family strain were expected to impede development of EF; adverse contexts in which responsibility is imposed may mitigate the otherwise beneficial effects. Accordingly, adolescents from higher SES households and with less family stress were expected to benefit from higher levels of responsibility, as indicated by better performance on the EF task. This line of research has potential to eventually inform our understanding of how certain parenting expectations and demands may influence neurodevelopment in adolescence, and the extent to which environmental contexts may alter neurodevelopmental and behavioral outcomes.

\section{2 | METHODS}

\section{1 | Participants}

Drug and alcohol naïve adolescents $(N=147$; age $=11-13$ years old) were recruited to participate in the Adolescent Development Study (ADS), a prospective, longitudinal study of the neural, cognitive, and behavioral precursors and consequences of adolescent drug and alcohol use in the greater Washington, DC metropolitan area. Participants were excluded on the basis of substance use, prior head injury, left handedness, neurodevelopmental disorders (e.g., epilepsy, autism spectrum disorders, and motor disorders), as well as other contraindications for magnetic resonance (MR) imaging (e.g., MR incompatible metal foreign bodies). The RTI International and Georgetown University Institutional Review Boards approved the study. All caregivers and youth provided consent or assent, respectively, prior to participating in the study.

A range of neurocognitive, behavioral, contextual, brain imaging, and demographic measures were acquired during a substance-naïve baseline assessment (i.e., Wave 1), and at 18- and 36-month follow-up visits (i.e., Waves 2 and 3, respectively) to capture cognitive and affective processes/patterns hypothesized to be predictive of drug/alcohol use initiation and escalation (see Fishbein, Rose, Darcey, Belcher, \& VanMeter, 2016, for complete description of the full sample, recruitment technique, and methods). The data presented here are based on a subsample of adolescents from the Wave 1 assessment who had both responsibility questionnaire and usable MRI data ( $N=108$; see Table 1 for sample demographics). Participants ranged from ages 11 to $14(M=12.65, S D=0.72)$ with 57 females.

\subsection{Measures}

\subsection{1 | Responsibility questionnaire}

After a thorough search, no existing instrument capturing specific aspects of level of responsibility were found; thus, we constructed a questionnaire to probe adolescents and their caregivers regarding adolescents' level of responsibility, demands, and expectations within the context of their family and home lives in the last 30 days. In particular, parents answered questions about their expectations of their adolescent to routinely complete certain tasks, while 
TABLE 1 Sample demographics

\begin{tabular}{|c|c|c|c|c|c|c|}
\hline & Total (N) & $\begin{array}{l}\text { Gender } \\
\text { (F:M) }\end{array}$ & $\begin{array}{l}\text { Age }(M(S D)) ; \\
\text { range in years }\end{array}$ & $\begin{array}{l}\text { Race/ethnicity (\% } \\
\text { W:L:B:other) }\end{array}$ & $\begin{array}{l}\text { Parental education } \\
\text { (M(SD); years) }\end{array}$ & $\begin{array}{l}\text { Household income } \\
\text { (M(SD); range) }\end{array}$ \\
\hline Total sample & 108 & $57: 51$ & $\begin{array}{l}12.65(0.72) \\
11-14\end{array}$ & 57\%:7\%:30\%:6\% & $16.45(2.86)$ & $\begin{array}{l}12.67(0.74) ; \\
11-14\end{array}$ \\
\hline Low SES group & 53 & $28: 25$ & $\begin{array}{l}12.56(0.78) \\
11-14\end{array}$ & 32\%:7\%:55\%:6\%** & $14.13(2.02)^{* *}$ & $\begin{array}{l}12.56(0.79) \\
11-14\end{array}$ \\
\hline
\end{tabular}

Note: Household income range: $1=<\$ 5,000$ per year to $15=\$ 200,000$ or more. ${ }^{* *} p<.01$ group difference between low and high SES groups based on $t$-test or $\chi^{2}$ analyses.

Abbreviations: B, Black/African American; L, Latino/a; W, White/Caucasian.

adolescents answered questions about their perceptions of their parent's expectations as well as their actual responsible behaviors. Adolescents responded to 30 questions (15 items for perceived parental expectations, 15 for actual behaviors). Parents responded to 9 questions regarding expectations of adolescent behavior, all of which corresponded to the adolescent questions. Behaviors in the past 30 days were surveyed on a Likert scale of never, a few times per month, every week, every few days, and every day. Example behaviors included: setting the table, washing dishes, making one's bed, cleaning the house, and doing laundry. Survey items that were not normally distributed were excluded (e.g., shopping for household, cooking for family). Moreover, two items with a lack of affirmative responses were excluded; i.e., making a financial contribution to the household or to one's education garnered $<7 \%$ affirmative responses. Following these data cleaning procedures, 7 adolescentreported expectation items, 7 adolescent-reported actual behavior items, and 5 parent-reported expectation items remained. To ascertain both actual adolescent behavior and parental expectations of adolescents, these items were summed (i.e., 7 adolescent report items and 5 parent report items; $M=26.90, S D=7.14$; range $=12-$ 44). We excluded adolescent perceived expectations for two reasons: (a) to avoid biasing the survey toward adolescent responses (i.e., having two assessments of adolescent perceptions vs. only one of parent report), which could distort the validity of the scale; and (b) to gain both an adolescent and a parent perspective on adolescents' responsible behaviors. Interitem correlations between adolescent and parent report are reported in Table 2. Summed self-report actual and parent expected behaviors were moderately correlated $(r=.51$, $p<.01)$. To examine whether variance in the 12 items from selfand parent-report was convergent, we also performed a Principal Component Analysis (PCA) with a Promax (oblique) rotation. The PCA revealed two components and indicated that the 12 items largely converged onto component 1 , suggesting that combining the self- and parent-report measures is statistically appropriate. Internal reliability of the measure was acceptable (Cronbach's $\alpha=0.74$ ), increasing confidence in the overall structure of the survey.

\subsubsection{Stockings of Cambridge}

The Stockings of Cambridge (SOC) task is a strategy and problemsolving task, which is an adaptation of the commonly used Tower of Hanoi task (Shallice, 1982). The SOC is administered on a tablet via CANTAB® (Cambridge Cognition, Cambridge, UK; http://www. cambridgecognition.com/cantab) (Cambridge Neuropsychological Testing Automated Battery, 2012) and is typically completed within $10 \mathrm{~min}$. In the task, participants were given two displays on the top and bottom of the screen, which both included three stockings

TABLE 2 Correlations between adolescents' self-reported actual responsibility and parent report of expected behaviors

\begin{tabular}{|c|c|c|c|c|c|}
\hline Variables & $\begin{array}{l}\text { Parent expect - } \\
\text { setting table }\end{array}$ & $\begin{array}{l}\text { Parent expect - } \\
\text { washing dishes }\end{array}$ & $\begin{array}{l}\text { Parent expect - } \\
\text { making bed }\end{array}$ & $\begin{array}{l}\text { Parent expect - } \\
\text { cleaning house }\end{array}$ & $\begin{array}{l}\text { Parent expect } \\
\text { - laundry }\end{array}$ \\
\hline Self-actual - setting table & $0.46^{* *}$ & 0.12 & 0.01 & -0.02 & 0.07 \\
\hline Self-actual - washing dishes & & $0.37^{* *}$ & 0.05 & 0.12 & 0.07 \\
\hline Self-actual - making bed & & & $0.39^{* *}$ & -0.03 & 0.05 \\
\hline Self-actual - cleaning house & & & & $0.31^{* *}$ & 0.13 \\
\hline Self-actual - doing laundry & & & & & $0.49^{* *}$ \\
\hline \multicolumn{6}{|l|}{$\begin{array}{l}\text { Self-actual - taking care of } \\
\text { pets }^{\text {a }}\end{array}$} \\
\hline $\begin{array}{l}\text { Self-actual - cleaning own } \\
\text { room }^{a}\end{array}$ & & & & & \\
\hline
\end{tabular}

Note: ${ }^{* *} p<.01$. Pearson correlations in bold are between items reflecting the same actual and expected behaviors.

${ }^{\mathrm{a}}$ Parents were not asked about adolescent behavior for this item. 
containing three colored balls each. The top display contained a pattern that the participants were instructed to duplicate in the bottom display. Importantly, participants were instructed to duplicate the top display in as few moves as possible by moving the balls one at a time. Outcome measures include initial thinking time, level of difficulty reached, and the mean number of moves used. In light of the mean age of participants and potential ceiling effects at the easier level in typically developing, older developmental samples (e.g., Gau \& Shang, 2010; Matthews, Coghill, \& Rhodes, 2008), we focused on performance outcomes (i.e., mean number of moves needed to solve the problem) for the most difficult level in our analyses. Specifically, we examined mean number of moves in a problem set that requires a minimum of five moves to complete, rather than the easier problem sets with that require one to four moves to complete.

\subsection{3 | Socioeconomic status and family stress}

Family socioeconomic status (SES) was calculated based on parental education and income using a method adapted from Manuck, Phillips, Gianaros, Flory, and Muldoon (2010) (also see McQuaid, Darcey, Avalos, VanMeter, \& Fishbein, 2019). A standardized education z-score was calculated for each participant based on an average of maternal and paternal years of education. A standardized income $z$-score was calculated for each participant based on caregiver report of annual household income prior to taxes (i.e., from $\$ 5,000$ to $\geq \$ 200,000$ ). The final SES index was calculated based on the average of the standardized education and income variables for each participant. These values were then restandardized to create a distribution with a zero-centered mean and a standard deviation of 1 . In several analyses, a median split of SES was used to assess differences between high and low SES groups. However, within those subgroups SES was modeled as a continuous variable.

The Drug Use Screening Inventory-Revised (DUSI-R; Tarter, 1990) was used to assess household stress using the family systems subscale. Specifically, the DUSI-R includes 14 questions about family environment, including items about general household stress; for example, "Did you feel in danger at home?"; "Did you have frequent arguments with your children, parents, or spouse which involved yelling and screaming?"; and "Has a member of your family been arrested?". This scale was used to account for general household stress as a potential correlate of SES and a contributor to variability in responsibility.

\subsection{4 | MRI data acquisition}

Participants were scanned using a 3T Siemens Tim Trio MRI machine (Erlangen, Germany) with a 12-channel head coil. Foam padding was placed around participants' heads to minimize head motion. A high-resolution T1-weighted anatomical scan was acquired using a magnetization prepared rapid acquisition gradient echo (MPRAGE) protocol with the following parameters: TR/TE $=1900 \mathrm{~ms} /$ $\mathrm{TE}=2.52 \mathrm{~ms}, \mathrm{TI}=900 \mathrm{~ms}$, flip angle $=9^{\circ}, \mathrm{FOV}=250 \mathrm{~mm}^{2}, 176$ slices with a thickness of $1.0 \mathrm{~mm}$, effective resolution $=1 \mathrm{~mm}^{3}$, and scan time $=4 \mathrm{~min}, 18 \mathrm{~s}$. Prior to scanning, participants underwent training to prepare for the scanning environment.

\subsection{5 | MRI data quality control}

Prior to the FreeSurfer analysis, MPRAGEs were inspected for image quality by at least three trained raters. These structural images were scored on a scale of 1 (high quality) to 5 (low quality) for ghosting and ringing. Clipping and wrapping were scored with either a 1 (low quality) or 0 (high quality). A single quality control (QC) metric was calculated using the following computation (QC = $4 \times$ wrap $+10 \times$ clip $+2 \times$ ring $+1 \times$ ghost). Images with a QC metric $>11$ were deemed to be of poor overall quality and excluded from further analysis $(N=23)$.

\subsection{6 | MRI data processing}

Cortical reconstruction and volumetric segmentation were performed using the Freesurfer image analysis suite (v6.0) (i.e., the recon-all pipeline; see http://surfer.nmr.mgh.harvard.edu/ for documentation). The technical details of these procedures are described in prior publications (e.g., Fischl et al., 2002; Reuter, Rosas, \& Fischl, 2010; Reuter, Schmansky, Rosas, \& Fischl, 2012). Briefly, image processing included motion correction and averaging (Reuter et al., 2010) of volumetric T1-weighted images, removal of nonbrain tissue (Ségonne et al., 2004), automated Talairach transformation, segmentation of the subcortical white gray matter (Fischl et al., 2002), intensity normalization (Sled, Zijdenbos, \& Evans, 1998), tessellation of the gray matter white matter boundary, automated topology correction (Ségonne, Pacheco, \& Fischl, 2007), and surface deformation following intensity gradients (Fischl \& Dale, 2000). Cortical thickness estimates of regions implicated in EF were derived from the Destrieux 2009 Atlas available in the FreeSurfer package (Destrieux, Fischl, Dale, \& Halgren, 2010). Regions selected included bilateral anterior cingulate, precuneus, middle frontal cortex, orbital frontal cortex, frontal pole, and superior frontal cortex, all of which have been identified as regions pertinent to EF (e.g., Collette, Hogge, Salmon, \& Van der Linden, 2006; Mace, Waters, Sawyer, Turrisi, \& Gansler, 2019).

\section{3 | Data analysis}

Linear regression analyses with the summed responsibility score were conducted to determine whether it predicted cortical thickness in regions associated with EF (i.e., bilateral orbital, middle, and superior frontal cortices, frontal pole, anterior cingulate, and 
precuneus). Importantly, because of the known age-related effects on cortical thickness (e.g., Tamnes et al., 2017), we included age as a first-level covariate in these analyses. Participant gender was not included as a covariate in any analyses, as there were no significant correlations between gender and our study variables (i.e., cortical thickness, responsibility, family stress, SES, and SOC performance; all $p>$.05). We also conducted hierarchical regression analyses to distinguish (a) the relative contributions of EF (SOC performance) and responsibility to cortical thickness and (b) whether responsibility is predictive of cortical thickness above and beyond EF (i.e., SOC performance). To do so, SOC performance was entered first into the model, followed by responsibility.

In separate linear regressions, we also ascertained whether contextual factors (DUSI family stress and SES) played a role in level of responsibility. Further hierarchical regression analyses were conducted to understand the relative contributions of SES, family stress, and responsibility to cortical thickness. As in prior studies, we did not control for total brain volume or intracranial volume, as this violates various statistical assumptions (e.g., Wierenga et al., 2018; Wierenga, Sexton, Laake, Giedd, \& Tamnes, 2017), including that equal variances are assumed between groups.

Based on results of analyses showing an association between SES and responsibility, we examined whether cortical thickness of regions that were significantly related to responsibility differed between high and low SES groups (i.e., median split) via linear regressions, controlling for age. Our purpose was to examine whether SES status (high or low) moderated the relationship between responsibility and cortical thickness. We also conducted confirmatory hierarchical regression analyses in each SES subgroup to examine whether responsibility, above and beyond variability in SES and family stress, predicted cortical thickness.

Finally, to explore the association between level of responsibility and EF as it relates to SES, we conducted additional linear regressions in high and low SES groups with performance in the SOC task (i.e., mean moves for the most difficult problem set) predicting responsibility.

(a)

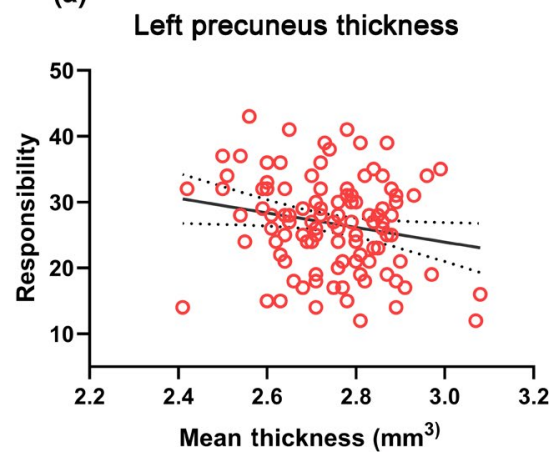

\section{3 | RESULTS}

\section{1 | Responsibility, executive functioning, and cortical thickness}

The first set of linear regression analyses focused on thickness measures in regions that support executive control functions (i.e., bilateral orbital, middle, and superior frontal cortices, frontal pole, anterior cingulate, and precuneus; see Figure 1 and Table 3). Consistent with our hypotheses, these analyses revealed that a higher level of responsibility in adolescents was associated with reduced cortical thickness in the left precuneus $\left(r^{2}=.06, p=.04\right)$ and right rostral middle frontal cortex $\left(r^{2}=.06, p=.04\right)$. Notably, age was not a significant predictor of cortical thickness in either region (left precuneus: $r^{2}=.02, p=.11$; right middle frontal: $r^{2}=.02, p=.13$ ). The hierarchical regression analyses focused on the relative contributions of responsibility and SOC performance (i.e., EF) on thickness measures revealed that $E F$ did not significantly contribute to cortical thickness in the left precuneus $\left(F_{(1,102)}=0.63, p=.43\right)$ or the right middle frontal $\operatorname{cortex}\left(F_{(1,101)}=0.00, p=.98\right.$; Tables S1 and S2). Above and beyond $E F$, greater responsibility uniquely predicted thinner left precuneus when added to the model $\left(F_{(1,101)}=4.03, p=.047\right)$. The overall model, however, was not significant $\left(F_{(2,101)}=2.34, p=.10\right)$. Likewise, above and beyond $E F$, greater responsibility uniquely predicted thinner right middle frontal cortex $\left(F_{(1,100)}=3.86, p=.05\right)$. The overall model was not significant $\left(F_{(2,100)}=1.93, p=.15\right)$. In the next set of analyses, we examined whether and to what extent contextual factors (i.e., SES and family stress) related to levels of responsibility and cortical thickness in these regions.

\subsection{Contextual influences on the association between responsibility and cortical thickness}

We first evaluated whether potential sources of environmental stress-specifically, SES and family stress (i.e., measured using the DUSI-R family subscale)-were associated with level of responsibility.

(b)

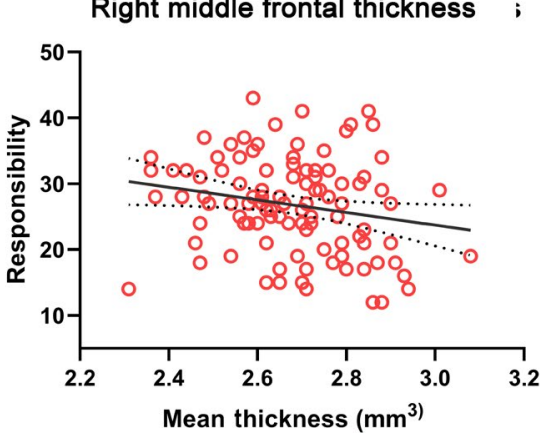

FIGURE 1 Regression results for responsibility and cortical thickness. Figure 1a. Linear regression analyses indicated correspondence between left precuneus cortical thickness and responsibility; (1b). Likewise, linear regression analyses indicated correspondence between right middle frontal gyrus thickness and responsibility. Both $1 \mathrm{a}$ and $1 \mathrm{~b}$ illustrate that with more responsibility, adolescents have thinner regions 
TABLE 3 Regressions with cortical thickness predicting responsibility

\begin{tabular}{|c|c|c|c|c|c|}
\hline Brain region & B & SE B & $\boldsymbol{\beta}$ & $t$ & $p$ \\
\hline $\begin{array}{l}\mathrm{L} \text { anterior } \\
\text { cingulate }\end{array}$ & -1.76 & 2.97 & -0.06 & -0.59 & .56 \\
\hline $\begin{array}{l}\mathrm{R} \text { anterior } \\
\text { cingulate }\end{array}$ & 2.35 & 3.46 & 0.07 & 0.68 & .50 \\
\hline $\mathrm{L}$ precuneus & -11.37 & 5.25 & -0.21 & -2.17 & $.04^{*}$ \\
\hline $\mathrm{R}$ precuneus & -8.37 & 4.81 & -0.17 & -1.74 & .09 \\
\hline $\begin{array}{l}\text { L rostral middle } \\
\text { frontal }\end{array}$ & -2.17 & 4.57 & -0.05 & -0.48 & .64 \\
\hline $\begin{array}{l}\text { R rostral middle } \\
\text { frontal }\end{array}$ & -9.47 & 4.46 & -0.20 & -2.12 & $.04^{*}$ \\
\hline $\begin{array}{l}\text { L medial orbital } \\
\text { frontal }\end{array}$ & -6.70 & 4.39 & -0.15 & -1.53 & .13 \\
\hline $\begin{array}{l}\mathrm{R} \text { medial orbital } \\
\text { frontal }\end{array}$ & -8.09 & 4.28 & -0.18 & -1.89 & .06 \\
\hline L frontal pole & -0.30 & 2.09 & -0.01 & -0.14 & .89 \\
\hline $\mathrm{R}$ frontal pole & -3.93 & 2.04 & -0.19 & -1.93 & .06 \\
\hline L superior frontal & -3.97 & 5.19 & -0.07 & -0.73 & .47 \\
\hline R superior frontal & -3.34 & 5.05 & -0.06 & -0.66 & .51 \\
\hline
\end{tabular}

Note: Significant $p$ values are bolded.

Abbreviations: $B$, unstandardized beta; $S E B$, standard error for unstandardized beta; $\beta$, standardized beta.

${ }^{*} p<.05$,

Age was not a significant predictor of responsibility in separate linear regressions with SES $\left(r^{2}=.02, p=.08\right)$ and family stress $\left(r^{2}=.03\right.$, $p=.09$ ). Linear regression results suggested that both SES and family stress are predictive of responsibility $\left(r^{2}=.07, p=.01 \& r^{2}=.10\right.$, $p=.01$, respectively). In both cases, increased environmental stress was predictive of higher level of responsibility (see Figure 2).

To disentangle how environmental stress and responsibility uniquely contribute to variance in cortical thickness in the previously identified brain regions, we ran hierarchical regression models for each region. As a direct test of our hypotheses, we entered SES into the first step of the model, followed by family stress and then responsibility. This three-step hierarchical regression allowed us to disentangle the relative contributions of each predictor to cortical thickness. Given the relatively high mean SES of this DC-based cohort and the lack of anticipated effects of SES for participants in higher economic brackets, in addition to constructing hierarchical regression models for the entire sample, we also considered the impact of responsibility for those in high versus low SES cohorts (i.e., median split) separately.

\subsection{1 | Whole group}

In the left precuneus, SES did not contribute to the variance in thickness $\left(F\left(_{1,106)}=0.73, p=.39\right.\right.$; Table S3). Similarly, adding family stress did not uniquely contribute to the variance in left precuneus $\left(F_{(1,105)}=0.18, p=.67\right)$, or was the overall model significant $\left(F_{(1,105)}=0.45, p=.64\right)$. However, when responsibility was added to the final step of the model, it did account for a significant amount of additional variance in left precuneus thickness $\left(F\left(_{1,104)}=4.10\right.\right.$, $p=.04)$, but the overall model was not significant $\left(F_{(1,104)}=1.68\right.$, $p=.18)$. That is, higher level of responsibility alone predicted thinner left precuneus.

The same pattern of results was found for the right rostral middle frontal cortex for the whole sample (Table S4). That is, SES and family stress did not contribute to variance in thickness $\left(F_{(1,105)}=0.00\right.$, $\left.p=.96 \& F_{(1,104)}=0.04, p=.84\right)$ and the overall model was not significant $\left(F_{(2,104)}=0.02, p=.98\right)$. When responsibility was added to the final step of the model, it accounted for additional variance in region thickness $\left(F_{(1,103)}=4.56, p=.03\right)$. However, the overall model was not significant, $F_{(3,103)}=1.53, p=.21$. Together, these findings demonstrate that for the whole sample, responsibility uniquely contributed to thickness of cortical regions.

\subsubsection{High and low SES subgroups}

We considered whether there were linear associations between responsibility and cortical thickness (controlling for age) for each of

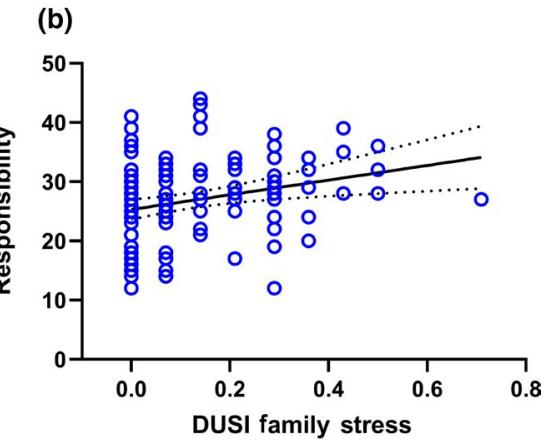

FIGURE 2 SES and DUSI family predicting responsibility levels. Figure 2a. Linear regression analyses revealed that adolescents' family socioeconomic status (SES) is associated with adolescent responsibility such that the lower SES group engages in higher levels of responsibility. Similarly, (2b) shows linear regression results for DUSI family stress and responsibility, indicating that with greater family stress, adolescents engage in higher levels of responsibility 
the regions that were noted in the initial analysis (i.e., precuneus and rostral middle frontal cortex) in SES groups separately (see Table 4). In the low SES group, age was not a significant predictor of cortical thickness in either region (left precuneus: $r^{2}=.01, p=.64$; right middle frontal: $r^{2}=.01, p=.59$ ). Conversely, in the high SES group, age was a significant predictor of cortical thickness in the left precuneus $\left(r^{2}=.10, p=.01\right)$ but not the right middle frontal cortex $\left(r^{2}=.06\right.$, $p=.06)$. Controlling for age, in the low SES group, level of responsibility was negatively associated with cortical thickness in the left precuneus $\left(r^{2}=.15, p=.01\right.$; Figure $\left.3 a\right)$, while in the high SES group, the same association was not found $\left(r^{2}=.00, p=.98\right.$; Figure $\left.3 b\right)$ Likewise, in the low SES group, higher levels of responsibility significantly predicted thinner right middle frontal cortex $\left(r^{2}=.11, p=.02\right.$; Figure $3 c$ ), while no such associations were found in the high SES group $\left(r^{2}=.00, p=.76\right.$; Figure $\left.3 d\right)$.

To confirm these results, we repeated our hierarchical regression models to examine whether responsibility, above and beyond SES and family stress, and predicted cortical thickness in each group. In the low SES group (Table S5), SES significantly predicted cortical thickness in the right middle frontal cortex $\left(F_{(1,46)}=10.85, p=.002\right)$. Adding family stress to the model did not account for any additional variance in right middle frontal thickness $\left(F_{(1,45)}=0.16, p=.69\right)$, although the model continued to be significant $\left(F_{(2,45)}=5.41, p=.01\right)$. In the final step, adding responsibility to the model did not contribute enough additional variance to result in a significant $R^{2}$ change $\left(F_{(1,44)}=2.50, p=.12\right)$. The overall model remained significant $\left(F_{(3,44)}=4.56, p=.01\right)$. For the left precuneus (Table S6), variability in SES significantly predicted cortical thickness $\left(F_{(1,47)}=6.15, p=.02\right)$. Adding family stress to the model did not add any additional variance $\left(F_{(1,46)}=0.39, p=.54\right)$ and the model was no longer significant $\left(F_{(2,46)}=3.23, p=.05\right)$. Finally, adding responsibility to the model contributed significant additional variance to the model $\left(F_{(1,45}=5.24\right.$ $p=.03)$, and the overall model was significant $\left(F_{(3,45)}=4.10, p=.01\right)$.

In the high SES group (Table S7), in the right middle frontal cortex, SES also significantly predicted cortical thickness $\left(F_{(1,55)}=7.11\right.$, $p=.01$ ). Family stress did not contribute any additional variance to the model $\left(F_{(1,54)}=0.42, p=.52\right)$, although the overall model remained significant $\left(F_{(2,54)}=3.72, p=.03\right)$. Adding responsibility in the final step did not add variance to the model $\left(F_{(1,53)}=0.00, p=.95\right)$, and the model was no longer significant $\left(F_{(3,53)}=2.43, p=.08\right)$. In the left precuneus (Table S8), SES did not predict thickness
$\left(F_{(1,55)}=1.01, p=.32\right)$. In the next step, adding family stress to the model did not contribute additional variance $\left(F_{(1,54)}=0.00, p=.94\right)$ and the model was not significant $\left(F_{(1,54)}=0.50, p=.61\right)$. In the final step, adding responsibility to the model did not add additional variance $\left(F_{(1,53)}=0.00, p=.99\right)$ and the overall model was not significant $\left(F_{(3,53)}=0.33, p=.81\right)$.

\subsection{3 | Contextual influences on executive functioning}

To further elucidate whether responsibility in different economic contexts impacts cognitive processes in adolescents, we considered the degree of correspondence between level of responsibility and performance on an EF task (SOC). Given the SES group specific effects that were noted for cortical thickness, analytic models included separate regression analyses for low and high SES groups with responsibility predicting performance on participants' mean number of moves in the most difficult problem set. Findings revealed that, in the low SES group, there was no correspondence between responsibility and performance on the SOC (Figure 4a). In contrast, in the high SES group, higher level of responsibility corresponded to better performance on the SOC (i.e., fewer overall moves), $r^{2}=.11$, $p=.01$ (Figure 4b).

\section{4 | DISCUSSION}

To our knowledge, this preliminary study is the first to focus specifically on the impacts of actual and expected level of responsibility within the home on adolescent brain development. Our findings suggest that thinning of cortical regions crucial to EF may be related to higher levels of responsibility. Notably, we found that responsibility was predictive of cortical thinning in EF regions, above and beyond EF performance in a problem-solving task. Moreover, we found that the strength and direction of the relationship between responsibility and cortical thinning was related to SES, and occurred above and beyond age. These results are consistent with prior work demonstrating significant negative impacts of lower SES environments on children's and adolescents' brain structure (e.g., Johnson et al., 2016). The present

\begin{tabular}{llllll} 
Brain region & B & SE B & $\boldsymbol{\beta}$ & $\boldsymbol{t}$ & $\boldsymbol{p}$ \\
\hline $\begin{array}{l}\text { Low SES } \\
\text { L precuneus }\end{array}$ & -0.01 & 0.00 & -0.39 & -2.88 & $.006^{* *}$ \\
$\quad$ R rostral middle frontal & -0.01 & 0.00 & -0.42 & -3.16 & $.003^{* *}$ \\
\hline High SES & & & & & \\
$\quad$ L precuneus & 0.00 & 0.00 & 0.00 & 0.03 & .98 \\
R rostral middle frontal & 0.00 & 0.00 & 0.04 & 0.29 & .77 \\
\hline
\end{tabular}

TABLE 4 Regression results for responsibility predicting cortical thickness in low and high SES groups

Note: Significant $p$ values are bolded.

${ }^{* *} p<.01$. 
(a)

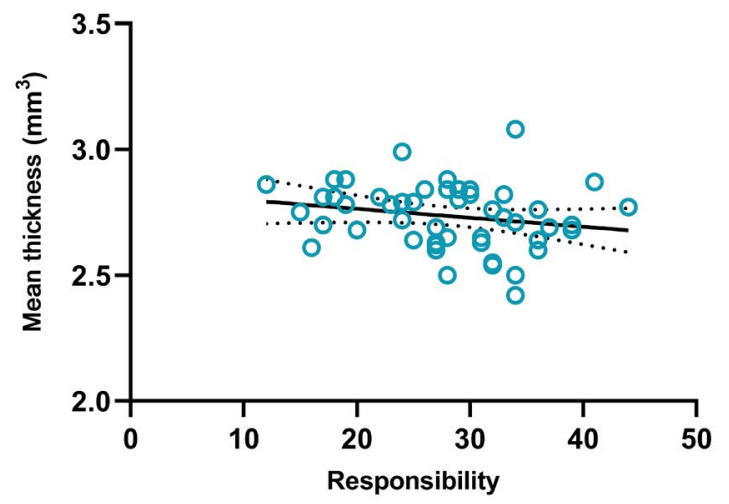

(b)

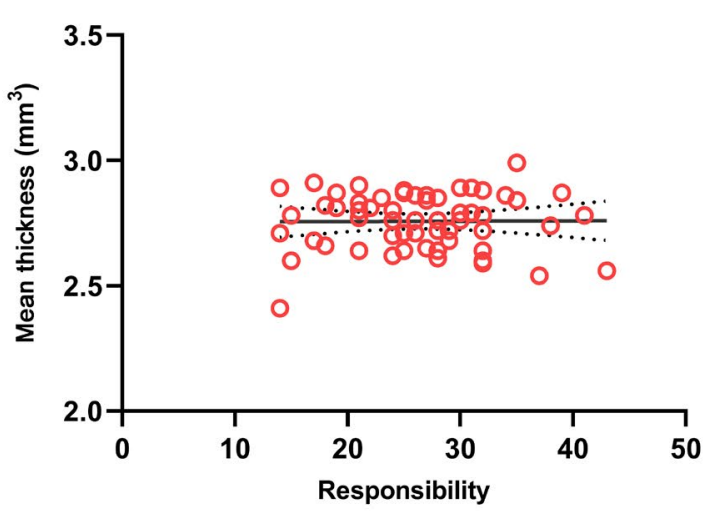

(c) Low SES: Right middle frontal

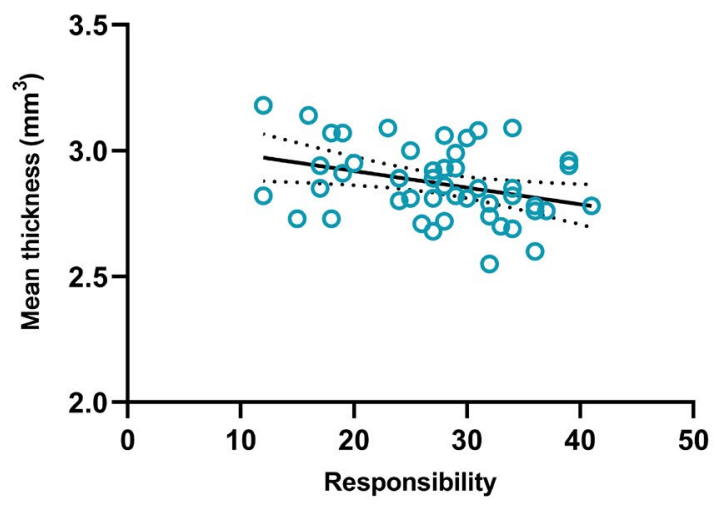

(d)

High SES: Right middle frontal

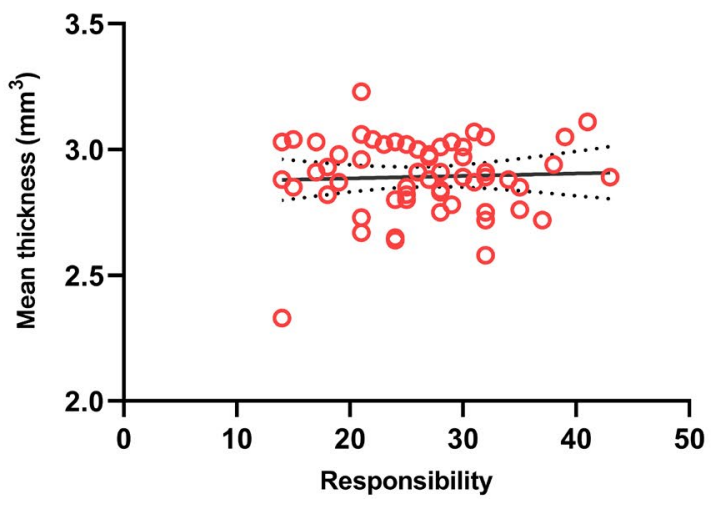

FIGURE 3 Regression results for responsibility and cortical thickness in low and high SES groups. Linear regression results in Figure 3a illustrate that in lower SES adolescents, greater levels of responsibility correspond to thinner left precuneus. Conversely, (3b) shows that in the higher SES adolescents, there is no association between responsibility and left precuneus thickness. Regression results in (3c) show that lower SES adolescents' greater levels of responsibility are significantly associated with thinner right middle frontal gyrus. Finally, (3d) exhibits in the higher SES group, there is no association between level of responsibility and right middle frontal gyrus thickness

(a)

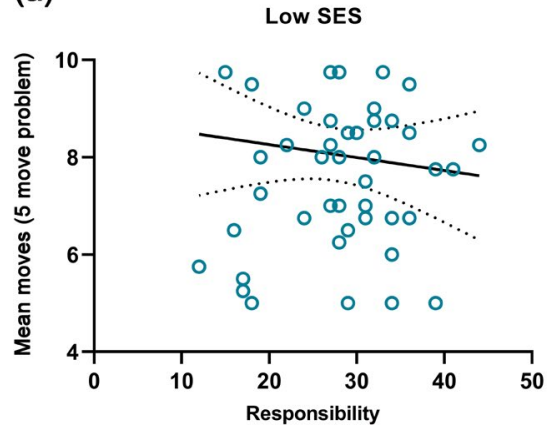

(b)

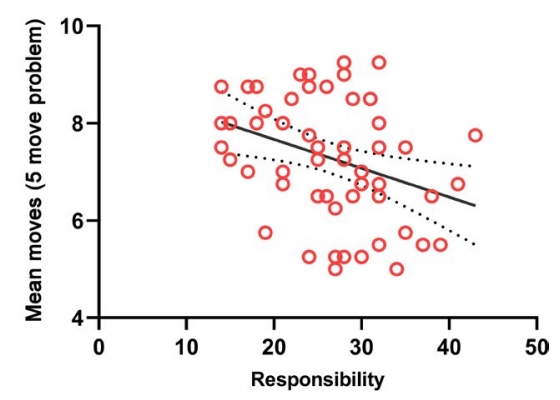

FIGURE 4 Regression results for responsibility predicting soc performance in low and high SES groups. Linear regression analyses revealed that socioeconomic status (SES) moderates the association between responsibility and performance on the Stockings of Cambridge (SOC) task. In (4a), the lower SES group does not show correspondence between responsibility and performance on the SOC. In contrast, (4b) illustrates that in the high SES group, greater levels of responsibility relate to superior performance on the SOC task

study introduces a new variable - level of responsibility - into that constellation of potential influencers; however, further explication is needed.
There are three core findings of particular interest. First, greater responsibility corresponded to thinner cortical regions implicated in EF (i.e., left precuneus and right middle frontal cortex; Burzynska 
et al., 2012; Munro et al., 2018). Second, environmental contextual factors - specifically SES and family stress - played a role in the association between responsibility and cortical thickness. Given that adolescents with lower SES and higher family stress exhibited greater levels of responsibility, we explored further and found that SES moderated the effect of responsibility on cortical thickness in regions critical to EF. That is, within the lower SES group, greater levels of responsibility corresponded to thinner regions (i.e., left precuneus and right middle frontal cortex). Conversely, the higher SES group of adolescents did not show this pattern of cortical thinning. And third, the higher SES group evinced a behavioral advantage, with greater responsibility relating to better EF performance (i.e., SOC). In contrast, we did not find correspondence between EF and responsibility in the lower SES group. Of note, there was no association between this behavioral advantage in the higher SES group and cortical thickness.

Our initial finding that responsibility corresponds to cortical thickness in neural regions implicated in EF is consistent with the notion that responsibility may be beneficial to adolescents and may relate to healthy cortical thinning patterns. The significance of this finding is highlighted by the fact that chronological age did not contribute to the relationship; generally, we would expect age-related cortical thinning to occur in these regions during adolescence (Zhou et al., 2015). The implication is that adolescents engaging in greater levels of responsibility are experiencing thinning in brain regions implicated in EF; however, only under certain conditions. Specifically, the relationship appears to be largely driven by the socioeconomic stratification of our participants. One interpretation may be that stress conferred through low resource environments counteracts potentially positive behavioral effects of responsibility, as indicated by EF performance. More specifically, greater responsibility may promote cortical thinning and have the potential to lead to improved EF skills. However, in the context of stressors that are linked to responsibility, the actual performance on EF tasks shows no behavioral benefit. In other words, adolescents who are exposed to stressors and have greater responsibility may mature faster neurally, with EF behavioral performance lagging behind in the short term. In contrast, greater responsibility in higher SES adolescents may not be "stressful" enough to drive brain development, perhaps because responsibilities are performed in a family context with fewer stressors and/or are not necessary to the same extent.

Specifically, lower SES adolescents in our sample engaged in higher levels of responsibility. Prior work has shown that more stressful family environments may result in reliance of caregivers on adolescents to contribute more to daily family functioning via responsible household behaviors, which may actually be burdensome to adolescents (Telzer \& Fuligni, 2009). The current investigation builds upon previous studies by incorporating indices of brain structure to determine whether this practice has an effect on neurodevelopment. Although family stress and responsibility corresponded in our sample, it is unclear whether the association between higher levels of responsibility and brain architecture presents a risk or protective factor in lower SES adolescents. One interpretation is that greater responsibility confers additional stress for adolescents, and acts as a risk factor for premature thinning. In other words, premature cortical thinning and/or chronic stress-induced dendritic atrophy may be reflected in thinner cortical regions. Prior animal models have shown that chronic stress may induce localized dendritic spine loss, with reports of localized spine loss in medial prefrontal regions (Arnsten, Raskind, Taylor, \& Connor, 2015; Liston et al., 2006; Radley et al., 2005). Our findings of cortical thinning in middle frontal cortex in lower SES adolescents engaging in greater responsibility are consistent with dendritic spine loss. A parallel literature has introduced the notion of a "stress-acceleration" process, whereby early life stress accelerates aspects of neurodevelopment with potential evolutionary advantages, even if developmentally non-normative (Herzberg \& Gunnar, 2020; Tyborowska et al., 2018). These studies might suggest that higher levels of responsibility for adolescents in economically disadvantaged environments exacerbate the experience of stress, resulting in greater, premature cortical thinning. As the present study did not measure the incidence or severity of early life stress, this explanation requires further inquiry.

Another interpretation is that responsibility may be a potentially protective factor by bolstering cortical thinning in regions related to EF in lower SES environments. In our data (Figure 3c,d), lower SES adolescents seem to have comparable levels of cortical thickness at greater levels of responsibility to the higher SES adolescents in the right middle frontal cortex, which may be suggestive of a "normalizing" effect of responsibility in the lower SES group. This possibility seems less plausible when considering prior work showing that cortical thinning may be initiated earlier in adolescents in lower SES environments, presumably due to higher levels of stress, as surmised above (Piccolo et al., 2016). It is also notable that with greater responsibility, the lower SES adolescents do not seem to exhibit the same performance advantages in the EF task as the higher SES adolescents do.

In contrast, the higher SES group appeared to benefit from engaging in more responsible behaviors in terms of their EF skills. There is a vast literature documenting the ways in which individuals from enriched environments have enhanced EF skills compared to individuals from environments with fewer resources (Sarsour et al., 2011; Ursache, Noble, \& Blair, 2015). Our findings add to this body of work by showing that responsibility is also associated with better performance on an EF task in the context of enriched environments. It is possible that, for higher SES adolescents, engaging in greater levels of responsibility is supportive of optimal EF development and skills. Alternatively, this finding may suggest that adolescents with enhanced EF skills are more likely to elect to engage in responsible behaviors.

A number of limitations temper definitive conclusions. First, the current investigation was not longitudinal in nature; thus, it is not possible to infer causality regarding the impact of level of responsibility on patterns of cortical thinning. Future work on this topic would benefit from examining the extent to which the level of responsibility or developmental changes in level of responsibility are predictive of changes in cortical thinning in neural regions implicated 
in planning, decision-making, self-regulation, and even prosociality. Longitudinal studies could also determine whether and to what extent adolescents more likely to assume responsibility may have inherently healthier brain development due to other corollary characteristics (e.g., personality, executive functioning) or if becoming responsible drives certain facets of brain development. Second, and relatedly, it will be important for future investigations to integrate multimodal imaging methods to discern correspondence between structure (e.g., VBM, DTI) and function (e.g., functional connectivity, resting state, task-dependent $\mathrm{fMRI}$ ) to parse out the relationships reported here.

Third, there is a lack of well-established measures of adolescent responsibility in the field. Although our measurement of responsibility incorporated both parent and adolescent reports, only household responsibilities were assessed. Future studies examining responsibility during adolescence could expand upon the current study by exploring different types of responsibility. For example, examining the potentially differential effects of types of responsibility in various settings (e.g., volunteer work, sports team participation, self-selected leadership opportunities) versus enforced or obligatory responsibility (e.g., parentally driven responsibilities, homework, etc.) on brain development could have significant implications for future research on the impacts of experience on adolescent brain development and successful transitions to adulthood.

Finally, our sample was recruited from a relatively affluent area of the country, making the sample higher SES compared to the broader US demographic. To minimize the impact of this issue, our SES score was calculated to create a relative measure of SES for our specific sample. In addition, although the differences in our SES groups are minute, our findings are consistent with prior research demonstrating that even minor differences in SES, particularly in lower SES groups, can have pervasive impacts on adolescent brain structure development (Hair et al., 2015; Noble et al., 2015). Future work examining how SES moderates effects of responsibility on adolescent brain structure would benefit from recruiting a more economically diverse sample and incorporating measures of perceived SES. That is, measures of perceived SES have been shown to be predictive of an array of developmental outcomes, including structural brain development (Brito \& Noble, 2014; Quon \& McGarth, 2014).

\section{1 | Implications and Conclusions}

The variability in level of social demands and expectations within the home may portend different neurodevelopmental trajectories, with some adolescents showing more protracted development while others exhibiting more normative maturation of neural circuits, particularly those that subserve dimensions of executive cognitive functioning, social competency skills, and self-regulation of behavior. As suggested by the preliminary findings reported herein, family SES is one condition that may influence different neurodevelopmental outcomes in the context of responsibility expectations within the home. Given that the brain's experience dependence is not contingent upon any one type of experience, countless factors influence final outcomes, many of which we did not measure here. Thus, isolating the impacts of level of responsibility will require careful sampling and parsing of both study participants and conditions, including mediators and moderators of divergent trajectories. These results, however, are thought provoking by raising the possibility that placing developmentally appropriate expectations on children and youth may be advantageous for neurodevelopment and adaptive functioning in the long term, but perhaps only in the presence of a supportive, nurturing, and adequately resourced environment.

Heightened neuroplasticity during adolescence represents a prime developmental period for prevention efforts designed to mitigate environmental adversities. Although the negative effects of home environments on adolescent neurodevelopment tend to be well documented, less attention has been paid to the effects of positive, nurturing environments (Fishbein, Michael, Guthrie, Carr, \& Raymer, 2019). In support of the ability to override, to some extent, negative environmental influences on functioning, there are a few promising intervention studies that are of particular relevance to the current investigation (Blair \& Raver, 2016; Brody et al., 2017). For example, Brody and colleagues show encouraging effects on adolescents' neurodevelopmental outcomes in economically disadvantaged families who received a supportive parenting intervention (Brody et al., 2017). Specifically, this work suggests that compared to controls, adolescents, and their parents who received a supportive parenting intervention showed protective effects, such that poverty-related volume reductions were not indicated in hippocampus and amygdalae at age 25 (Brody et al., 2017). A growing body of literature from prevention science supports the notion that positive psychosocial environmental input, particularly nurturing environments, can bolster normative brain development and adaptive behavior in adolescents and even buffer against maladaptive neurodevelopmental trajectories. Similarly, instilling developmentally appropriate responsibility in adolescents may provide a unique opportunity for skill building and teaching applied by caregivers; preventative interventions focusing on supportive parenting incorporating adolescent responsibility could provide a promising avenue for promoting adaptive functioning skills and general EF skills that are critical to adolescence and the transition to emerging adulthood.

\section{ACKNOWLEDGMENTS}

This research was supported by the following grants by the NIH/ NIAAA 1R01AA019983-01 and 3R01AA019983-02S1. In addition, research reported in this publication was supported by the National Institutes of Health, Eunice Kennedy Shriver National Institute of Child Health and Human Development under Award Number P5OHD089922. The content is solely the responsibility of the authors and does not necessarily represent the official views of the National Institutes of Health. The authors declare no conflicts of interest.

\section{DATA AVAILABILITY STATEMENT}

The data that support the findings of this study are available from the corresponding author upon reasonable request. 


\section{ORCID}

Giorgia Picci iD https://orcid.org/0000-0002-0700-4739

Emma J. Rose (iD https://orcid.org/0000-0001-5365-4794

John W. VanMeter (iD https://orcid.org/0000-0002-7012-5197

Diana H. Fishbein (iD https://orcid.org/0000-0003-1644-2762

\section{REFERENCES}

Arnsten, A. F., Raskind, M. A., Taylor, F. B., \& Connor, D. F. (2015). The effects of stress exposure on prefrontal cortex: Translating basic research into successful treatments for post-traumatic stress disorder. Neurobiology of Stress, 1, 89-99. https://doi.org/10.1016/j. ynstr.2014.10.002

Blair, C., \& Raver, C. C. (2016). Poverty, stress, and brain development: New directions for prevention and intervention. Academic Pediatrics, 16, S30-S36. https://doi.org/10.1016/j. acap.2016.01.010

Boelema, S. R., Harakeh, Z., Ormel, J., Hartman, C. A., Vollebergh, W. A., $\&$ van Zandvoort, M. J. (2014). Executive functioning shows differential maturation from early to late adolescence: Longitudinal findings from a TRAILS study. Neuropsychology, 28, 177.

Brito, N. H., \& Noble, K. G. (2014). Socioeconomic status and structural brain development. Frontiers in Neuroscience, 8, 1-12. https://doi. org/10.3389/fnins.2014.00276

Brody, G. H., Gray, J. C., Yu, T., Barton, A. W., Beach, S. R. H., Galván, A., ... Sweet, L. H. (2017). Protective prevention effects on the association of poverty with brain development. JAMA Pediatrics, 171, 46-52. https://doi.org/10.1001/jamapediatrics.2016.2988

Burzynska, A. Z., Nagel, I. E., Preuschhof, C., Gluth, S., Bäckman, L., Li, S.-C., ... Heekeren, H. R. (2012). Cortical thickness is linked to executive functioning in adulthood and aging. Human Brain Mapping, 33, 1607-1620. https://doi.org/10.1002/hbm.21311

Cambridge Neuropsychological Testing Automated Battery. (2012). Cambridge cognition. Cambridge, UK: Cambridge Cognition Limited.

Casey, B. J., Getz, S., \& Galvan, A. (2008). The adolescent brain. Developmental Review, 28, 62-77. https://doi.org/10.1196/ annals.1440.010

Collette, F., Hogge, M., Salmon, E., \& Van der Linden, M. (2006). Exploration of the neural substrates of executive functioning by functional neuroimaging. Neuroscience, 139, 209-221. https://doi. org/10.1016/j.neuroscience.2005.05.035

Destrieux, C., Fischl, B., Dale, A., \& Halgren, E. (2010). Automatic parcellation of human cortical gyri and sulci using standard anatomical nomenclature. Neurolmage, 53, 1-15. https://doi.org/10.1016/j.neuro image.2010.06.010

Evans, G. W., \& Kim, P. (2013). Childhood poverty, chronic stress, self-regulation, and coping. Child Development Perspectives, 7, 43-48. https://doi.org/10.1111/cdep.12013

Farley, J. P., \& Kim-Spoon, J. (2014). The development of adolescent self-regulation: Reviewing the role of parent, peer, friend, and romantic relationships. Journal of Adolescence, 37, 433-440. https:// doi.org/10.1016/j.adolescence.2014.03.009

Fischl, B., \& Dale, A. M. (2000). Measuring the thickness of the human cerebral cortex from magnetic resonance images. Proceedings of the National Academy of Sciences, 97, 11050-11055. https://doi. org/10.1073/pnas.200033797

Fischl, B., Salat, D. H., Busa, E., Albert, M., Dieterich, M., Haselgrove, C., ... Dale, A. M. (2002). Whole brain segmentation: Automated labeling of neuroanatomical structures in the human brain. Neuron, 33 , 341-355. https://doi.org/10.1016/S0896-6273(02)00569-X

Fishbein, D. H., Michael, L., Guthrie, C., Carr, C., \& Raymer, J. (2019). Associations between environmental conditions and executive cognitive functioning and behavior during late childhood: A pilot study. Frontiers in Psychology, 10, 1-12. https://doi.org/10.3389/ fpsyg.2019.01263

Fishbein, D. H., Rose, E. J., Darcey, V. L., Belcher, A. M., \& VanMeter, J. W. (2016). Neurodevelopmental precursors and consequences of substance use during adolescence: Promises and pitfalls of longitudinal neuroimaging strategies. Frontiers in Human Neuroscience, 10, 1-16. https://doi.org/10.3389/fnhum.2016.00296

Fjell, A. M., Grydeland, H., Krogsrud, S. K., Amlien, I., Rohani, D. A., Ferschmann, L., ... Walhovd, K. B. (2015). Development and aging of cortical thickness correspond to genetic organization patterns. Proceedings of the National Academy of Sciences, 112, 15462-15467. https://doi.org/10.1073/pnas.1508831112

Gau, S. S. F., \& Shang, C. Y. (2010). Executive functions as endophenotypes in ADHD: Evidence from the Cambridge Neuropsychological Test Battery (CANTAB). Journal of Child Psychology and Psychiatry, 51, 838-849. https://doi.org/10.1111/j.1469-7610.2010.02215.x

Giedd, J. N. (2004). Structural magnetic resonance imaging of the adolescent brain. Annals of the New York Academy of Sciences, 1021, 77-85.

Giedd, J. N., Blumenthal, J., Jeffries, N. O., Castellanos, F. X., Liu, H., Zijdenbos, A., ... Rapoport, J. L. (1999). Brain development during childhood and adolescence: A longitudinal MRI study. Nature Neuroscience, 2, 861-863. https://doi.org/10.1038/13158

Hair, N. L., Hanson, J. L., Wolfe, B. L., \& Pollak, S. D. (2015). Association of child poverty, brain development, and academic achievement. JAMA Pediatrics, 169, 822-829. https://doi.org/10.1001/jamapediat rics. 2015.1475

Herzberg, M. P., \& Gunnar, M. R. (2020). Early life stress and brain function: Activity and connectivity associated with processing emotion and reward. Neurolmage, 209, 1-12. https://doi.org/10.1016/j.neuro image.2019.116493

Hurd, N. M., Stoddard, S. A., \& Zimmerman, M. A. (2013). Neighborhoods, social support, and African American adolescents' mental health outcomes: A multilevel path analysis. Child Development, 84, 858-874. https://doi.org/10.1111/cdev.12018

Jaffee, S. R. (2017). Child maltreatment and risk for psychopathology in childhood and adulthood. Annual Review of Clinical Psychology, 13, 525-551. https://doi.org/10.1146/annurev-clinpsy-032816-045005

Jednoróg, K., Altarelli, I., Monzalvo, K., Fluss, J., Dubois, J., Billard, C., ... Ramus, F. (2012). The influence of socioeconomic status on children's brain structure. PLoS One, 7, 1-9. https://doi.org/10.1371/ journal.pone.0042486

Johnson, S. B., Riis, J. L., \& Noble, K. G. (2016). State of the art review: Poverty and the developing brain. Pediatrics, 137, e20153075. https://doi.org/10.1542/peds.2015-3075

Lam, C. B., Greene, K. M., \& McHale, S. M. (2016). Housework time from middle childhood through adolescence: Links to parental work hours and youth adjustment. Developmental Psychology, 52, 2071-2084. https://doi.org/10.1037/dev0000223

Lawson, G. M., Duda, J. T., Avants, B. B., Wu, J., \& Farah, M. J. (2013). Associations between children's socioeconomic status and prefrontal cortical thickness. Developmental Science, 16, 641-652. https:// doi.org/10.1111/desc.12096

Liston, C., Miller, M. M., Goldwater, D. S., Radley, J. J., Rocher, A. B., Hof, P. R., ... McEwen, B. S. (2006). Stress-induced alterations in prefrontal cortical dendritic morphology predict selective impairments in perceptual attentional set-shifting. Journal of Neuroscience, 26, 78707874. https://doi.org/10.1523/JNEUROSCI.1184-06.2006

Lovallo, W. R. (2013). Early life adversity reduces stress reactivity and enhances impulsive behavior: Implications for health behaviors. International Journal of Psychophysiology, 90, 8-16. https://doi. org/10.1016/j.ijpsycho.2012.10.006

Luby, J., Belden, A., Botteron, K., Marrus, N., Harms, M. P., Babb, C., ... Barch, D. (2013). The effects of poverty on childhood brain development: The mediating effect of caregiving and stressful life events. 
JAMA Pediatrics, 167, 1135-1142. https://doi.org/10.1001/jamap ediatrics.2013.3139

Mace, R. A., Waters, A. B., Sawyer, K. S., Turrisi, T., \& Gansler, D. A. (2019). Components of executive function model regional prefrontal volumes. Neuropsychology, 33, 1007-1019. https://doi.org/10.1037/ neu0000563

Manuck, S. B., Phillips, J., Gianaros, P. J., Flory, J. D., \& Muldoon, M. F. (2010). Subjective socioeconomic status and presence of the metabolic syndrome in midlife community volunteers. Psychosomatic Medicine, 72, 35-45. https://doi.org/10.1097/PSY.0b013e3181 c484dc

Matthews, K., Coghill, D., \& Rhodes, S. (2008). Neuropsychological functioning in depressed adolescent girls. Journal of Affective Disorders, 111, 113-118. https://doi.org/10.1016/j.jad.2008.02.003

McQuaid, G. A., Darcey, V. L., Avalos, M. F., VanMeter, J. W., \& Fishbein, D. H. (2019). Altered cortical development and psychiatric symptom risk in adolescents exposed to maternal stress in utero. Behavioural Brain Research, 375, 112-145. https://doi. org/10.1016/j.bbr.2019.112145

Munro, B. A., Weyandt, L. L., Hall, L. E., Oster, D. R., Gudmundsdottir, B. G., \& Kuhar, B. G. (2018). Physiological substrates of executive functioning: A systematic review of the literature. ADHD Attention Deficit and Hyperactivity Disorders, 10, 1-20. https://doi.org/10.1007/ s12402-017-0226-9

Niehaus, K., Rudasill, K. M., \& Rakes, C. R. (2012). A longitudinal study of school connectedness and academic outcomes across sixth grade. Journal of School Psychology, 50, 443-460. https://doi.org/10.1016/j. jsp.2012.03.002

Noble, K. G., Houston, S. M., Brito, N. H., Bartsch, H., Kan, E., Kuperman, J. M., ... Sowell, E. R. (2015). Family income, parental education and brain structure in children and adolescents. Nature Neuroscience, 18 , 773-778. https://doi.org/10.1038/nn.3983

Noble, K. G., Houston, S. M., Kan, E., \& Sowell, E. R. (2012). Neural correlates of socioeconomic status in the developing human brain. Developmental Science, 15, 516-527.

Piccolo, L. R., Merz, E. C., He, X., Sowell, E. R., \& Noble, K. G. (2016). Age-related differences in cortical thickness vary by socioeconomic status. PLoS One, 11, e0162511. https://doi.org/10.1371/journ al.pone. 0162511

Quon, E. C., \& McGrath, J. J. (2014). Subjective socioeconomic status and adolescent health: A meta analysis. Health Psychology, 33, 433-447. https://doi.org/10.1037/a0033716

Radley, J. J., Rocher, A. B., Miller, M., Janssen, W. G. M., Liston, C., Hof, P. R., ... Morrison, J. H. (2005). Repeated stress induces dendritic spine loss in the rat medial prefrontal cortex. Cerebral Cortex, 16, 313-320. https://doi.org/10.1093/cercor/bhi104

Raffaelli, M., Simpkins, S. D., Tran, S. P., \& Larson, R. W. (2018). Responsibility development transfers across contexts: Reciprocal pathways between home and afterschool programs. Developmental Psychology, 54, 559-570. https://doi.org/10.1037/dev0000454

Reuter, M., Rosas, H. D., \& Fischl, B. (2010). Highly accurate inverse consistent registration: A robust approach. Neurolmage, 53, 1181-1196. https://doi.org/10.1016/j.neuroimage.2010.07.020

Reuter, M., Schmansky, N. J., Rosas, H. D., \& Fischl, B. (2012). Withinsubject template estimation for unbiased longitudinal image analysis. Neurolmage, 61, 1402-1418. https://doi.org/10.1016/j.neuro image.2012.02.084

Riggio, H. R., Valenzuela, A. M., \& Weiser, D. A. (2010). Household responsibilities in the family of origin: Relations with self-efficacy in young adulthood. Personality and Individual Differences, 48, 568-573. https://doi.org/10.1016/j.paid.2009.12.008

Rossow, I., Felix, L., Keating, P., \& McCambridge, J. (2016). Parental drinking and adverse outcomes in children: A scoping review of cohort studies. Drug and Alcohol Review, 35, 397-405. https://doi. org/10.1111/dar.12319
Sarsour, K., Sheridan, M., Jutte, D., Nuru-Jeter, A., Hinshaw, S., \& Boyce, W. T. (2011). Family socioeconomic status and child executive functions: The roles of language, home environment, and single parenthood. Journal of the International Neuropsychological Society, 17, 120132. https://doi.org/10.1017/S1355617710001335

Ségonne, F., Dale, A. M., Busa, E., Glessner, M., Salat, D., Hahn, H. K., \& Fischl, B. (2004). A hybrid approach to the skull stripping problem in MRI. Neurolmage, 22, 1060-1075. https://doi.org/10.1016/j.neuro image.2004.03.032

Ségonne, F., Pacheco, J., \& Fischl, B. (2007). Geometrically accurate topology-correction of cortical surfaces using nonseparating loops. IEEE Transactions on Medical Imaging, 26, 518-529. https://doi. org/10.1109/TMI.2006.887364

Shallice, T. (1982). Specific impairments of planning. Philosophical Transactions of the Royal Society of London B, Biological Sciences, 298, 199-209. https://doi.org/10.1098/rstb.1982.0082

Sled, J. G., Zijdenbos, A. P., \& Evans, A. C. (1998). A nonparametric method for automatic correction of intensity nonuniformity in MRI data. IEEE Transactions on Medical Imaging, 17, 87-97. https://doi. org/10.1109/42.668698

Tamnes, C. K., Herting, M. M., Goddings, A.-L., Meuwese, R., Blakemore, S.-J., Dahl, R. E., ... Mills, K. L. (2017). Development of the cerebral cortex across adolescence: A multisample study of inter-related longitudinal changes in cortical volume, surface area, and thickness. Journal of Neuroscience, 37, 3402-3412. https://doi.org/10.1523/ JNEUROSCI.3302-16.2017

Tarter, R. E. (1990). Evaluation and treatment of adolescent substance abuse: A decision tree method. The American Journal of Drug and Alcohol Abuse, 16, 1-46. https://doi.org/10.3109/0095299900 9001570

Telzer, E. H., \& Fuligni, A. J. (2009). Daily family assistance and the psychological well-being of adolescents from Latin American, Asian, and European backgrounds. Developmental Psychology, 45, 1177-1189. https://doi.org/10.1037/a0014728

Telzer, E. H., Fuligni, A. J., Lieberman, M. D., \& Galván, A. (2013). Meaningful family relationships: Neurocognitive buffers of adolescent risk taking. Journal of Cognitive Neuroscience, 25, 374-387. https://doi.org/10.1162/jocn_a_00331

Telzer, E. H., Gonzales, N., \& Fuligni, A. J. (2014). Family obligation values and family assistance behaviors: Protective and risk factors for Mexican-American adolescents' substance use. Journal of Youth and Adolescence, 43, 270-283. https://doi.org/10.1007/s1096 4-013-9941-5

Telzer, E. H., Tsai, K. M., Gonzales, N., \& Fuligni, A. J. (2015). Mexican American adolescents' family obligation values and behaviors: Links to internalizing symptoms across time and context. Developmental Psychology, 51, 75-86. https://doi.org/10.1037/ a0038434

Tsai, K. M., Telzer, E. H., \& Fuligni, A. J. (2013). Continuity and discontinuity in perceptions of family relationships from adolescence to young adulthood. Child Development, 84, 471-484. https://doi. org/10.1111/j.1467-8624.2012.01858.x

Tyborowska, A., Volman, I., Niermann, H. C. M., Pouwels, J. L., Smeekens, S., Cillessen, A. H. N., ... Roelofs, K. (2018). Early-life and pubertal stress differentially modulate grey matter development in human adolescents. Scientific Reports, 8, 1-11. https://doi.org/10.1038/s4159 8-018-27439-5

Ursache, A., \& Noble, K. G. (2016). Neurocognitive development in socioeconomic context: Multiple mechanisms and implications for measuring socioeconomic status. Psychophysiology, 53, 71-82. https:// doi.org/10.1111/psyp.12547

Ursache, A., Noble, K. G., \& Blair, C. (2015). Socioeconomic status, subjective social status, and perceived stress: Associations with stress physiology and executive functioning. Behavioral Medicine, 41, 145154. https://doi.org/10.1080/08964289.2015.1024604 
van der Voort, A., Linting, M., Juffer, F., Bakermans-Kranenburg, M. J., Schoenmaker, C., \& van IJzendoorn, M. H. (2014). The development of adolescents' internalizing behavior: Longitudinal effects of maternal sensitivity and child inhibition. Journal of Youth and Adolescence, 43, 528-540. https://doi.org/10.1007/s10964-013-9976-7

Vidal-Pineiro, D., Parker, N., Shin, J., French, L., Jackowski, A. P., Mowinckel, A. M., ... Walhovd, K. B. (2019). Cellular correlates of cortical thinning throughout the lifespan. bioRxiv, 585786. https://doi.org/10.1101/585786

Wierenga, L. M., Bos, M. G. N., Schreuders, E., vd Kamp, F., Peper, J. S., Tamnes, C. K., \& Crone, E. A. (2018). Unraveling age, puberty and testosterone effects on subcortical brain development across adolescence. Psychoneuroendocrinology, 91, 105-114. https://doi. org/10.1016/j.psyneuen.2018.02.034

Wierenga, L. M., Sexton, J. A., Laake, P., Giedd, J. N., Tamnes, C. K. \& Pediatric Imaging, Neurocognition, and Genetics Study. (2017). A key characteristic of sex differences in the developing brain: Greater variability in brain structure of boys than girls. Cerebral Cortex, 28, 2741-2751. https://doi.org/10.1093/cercor/bh×154

Wray-Lake, L., \& Syvertsen, A. K. (2011). The developmental roots of social responsibility in childhood and adolescence. New Directions for Child and Adolescent Development, 2011, 11-25. https://doi. org/10.1002/cd.308
Wright, E. M., Fagan, A. A., \& Pinchevsky, G. M. (2013). The effects of exposure to violence and victimization across life domains on adolescent substance use. Child Abuse and Neglect, 37, 899-909. https:// doi.org/10.1016/j.chiabu.2013.04.010

Zhou, D., Lebel, C., Treit, S., Evans, A., \& Beaulieu, C. (2015). Accelerated longitudinal cortical thinning in adolescence. Neurolmage, 104, 138145. https://doi.org/10.1016/j.neuroimage.2014.10.005

\section{SUPPORTING INFORMATION}

Additional supporting information may be found online in the Supporting Information section.

How to cite this article: Picci G, Rose EJ, VanMeter JW,

Fishbein $\mathrm{DH}$. The moderating role of socioeconomic status on level of responsibility, executive functioning, and cortical thinning during adolescence. Dev Psychobiol. 2020;00:1-14. https://doi.org/10.1002/dev.22010 